\title{
Memory, Belief and Time
}

Brian Weatherson

I know a lot about the past. I know, for instance, that the Chicago White Sox won the 2005 baseball World Series. I remember that's true. I don't remember the event. I was in Australia, and it wasn't on television. I don't even remember the event of learning that the White Sox won. But I remember that they won. And to remember something is to, inter alia, know it is true. And to know something is to, inter alia, have a rational belief that it is true. ${ }^{1}$

So I have a rational belief that the White Sox won the 2005 baseball World Series. In virtue of what is this belief of mine rational? That's too big a question to answer here, so let's start narrowing it down. Is this belief rational in virtue of facts about how I now am, or historical facts about me? Call the former view a temporally local theory of rationality, and the latter a temporally extended view. Which of those is correct?

I'm going to defend the temporally extended view. In this respect I'm following recent work by David James Barnett (2015), though being a philosopher I'll quibble about his argument, put forward alternate reasons, and so on. But I'm agreeing with his big conclusion.

At least, I'm going to agree with a version of that conclusion. I'm an evidentialist about rationality, in a sense that I'll try to make clearer as we progress through the paper. So it's natural to convert the core question into a question about evidence, and about evidence acquisition. What is my evidence that the White Sox won the 2005 World Series, and in virtue of what do I have that evidence? Is it the currect fact that it mnemonically seems to me that the White Sox won, perhaps supplemented with some knowledge I have about the reliabiity of my mnemonic seemings? Or is it something more temporally extended? I'm going to argue that it is the latter.

My positive view, inspired to some extent by the evidence is knowledge view defended by Timothy Williamson (2000), is that the fact the White Sox won became part of my evidence some time in 2005, and has stayed in my evidence ever since. At the time this belief, and this knowledge, was grounded in further evidence, presumably perceptual evidence of what some computer screen looked like. But I came to know the White Sox won, and this became part of my evidence. An alternative view is that the visual seemings from 2005 are part of my evidence still. That's what the view of David Lewis (1996) implies. And yet another view is that the content of

\footnotetext{
${ }^{1}$ Thanks to Maria Lasonen-Aarnio, Ishani Maitra, and the participants at the excellent Belief, Action, and Rationality over Time conference for helpful comments on this paper. Special thanks to Jonathan Weisberg, whose comments on the version of the paper presented at Madison saved me from a number of mistakes.
} 
those perceptions, perhaps that ESPN is telling me the White Sox won, is still in my evidence. I don't like either of these latter views, but I'm not going to argue about them here. Rather, the focus is on whether evidence is contemporary or historical, and I want to argue for the class of historical theories over the class of contemporary theories.

\section{Evidentialism}

I'm interested in memory because it raises challenges for the evidentialist theory I'd like to defend. Evidentialism, as we'll start construing it, says that the doxastic attitudes it is rational to have depend entirely on the evidence one has. This is a version of evidentialism. I'm taking this to be a thesis both about partial beliefs, what are commonly called credences in the philosophical literature, and full beliefs. I have a lot to say elsewhere about the relationship between full and partial belief (Weatherson, 2012), but I won't be relying on those views here.

I am construing the 'dependence' in the statement of evidentialism rather weakly. It is just a claim that the evidence one has, and the attitudes it may be rational to hold, co-vary. Put another way, the rationality of doxastic attitudes supervenes on one's evidence, at least throughout worlds similar enough to this one. I am not defending the stronger claim that facts about what evidence one has are always explanatorily prior to facts about what doxastic attitudes it is rational to hold.

It is easy enough to imagine epistemologies that aim for this more ambitious, priority, thesis. David Lewis (1996), for instance, suggests we should understand evidence in terms of phenomenal states; two agents with the same phenomenology over time have the same evidence. It's arguable that facts about phenomenology are metaphysically prior to facts about rationality. So, if one was an evidentialist with Lewis's theory of evidence, it would be natural to think that facts about evidence didn't just subvene facts about rationality; the former provided full and perhaps reductive explanations for the latter.

I hold out no such hope for reductive explanations. Indeed, I'm closer in spirit to the kind of view you might read into Timothy Williamson (2000). As noted above, Williamson holds that one's evidence is all and only what one knows. This thesis has become known as $\mathrm{E}=\mathrm{K}$. The notation here is instructive. It is commonplace to introduce new terms by definition by putting the new term on the left-hand side of an equality sign. $A={ }_{d f} B$ means that $A$ is defined to be identical to $B$, not the other way around. The $\mathrm{E}=\mathrm{K}$ thesis suggests a form of evidentialism where evidence is in fact explanatorily posterior to rationality. Something is part of one's evidence in virtue of the fact that one knows it, and arguably one only knows what one rationally believes. 
I've been a bit coy in the previous paragraph about what I'm attributing to Williamson, and what I'm just saying can be read into him. That's because the view Williamson defends is not that rationality has explanatory priority, but that knowledge does. As he says in the first line of his book, his view is "knowledge first" (Williamson, 2000, v). And it's consistent with 'knowledge first' to say that the explanatory relationship between evidence and rationality is complicated and multi-directional. Although I don't endorse the knowledge first program, I agree with that last conclusion. The explanatory relationship between evidence and rationality is complicated and multi-directional. Evidentialism should not be construed as denying this claim.

The other way in which my version of evidentialism is weaker than it may be is that it really is restricted to being a claim about rationality. It isn't a claim about justification. For all I say here, maybe something other than evidence determines whether a doxastic attitude is justified. For example, it may be that only true beliefs are justified. I don't think that's true, but if it is it would be consistent with evidentialism as I'm construing it.

More importantly for what follows, evidentialism also isn't a claim about wisdom. It is very important to keep evaluations of agents apart from evaluations of acts or states. It is attitudes or states that are in the first instance rational or irrational. We can talk about rational or irrational agents, but such notions are derivative. Rational agents are those generally disposed to have rational attitudes, or be in rational states. Wisdom, on the other hand, is in the first instance a property of agents. Again, we can generalise the term to attitudes or states. A wise decision, for instance, is one that a wise person would make. But the wisdom of agents is explanatorily and analytically prior to the wisdom of their acts, judgments, decisions and attitudes. (I think that everything I've said in this paragraph is true of ordinary English. But I'm not committed to that, and it doesn't matter if I'm wrong. You can read this paragraph as stipulating that 'rational' is to be used as a term that in the first instance applies to states, and 'wise' is to be used as a term that in the first instance applies to agents, and little will be lost.)

Evidentialism is not a claim about the nature of wise agents. Perhaps a wise agent is one who always has rational attitudes. If so, then evidentialism will have quite strong implications for what wise agents are like. But that connection between wisdom and rationality is far from an obvious conceptual truth. For all I've said, it may well be wise to have doxastic attitudes that do not track one's evidence. That is consistent with evidentialism, provided we understand the relevant situations as being ones where it is unwise to have rational attitudes.

The most important recent work on the connection between rationality and wisdom is by Maria Lasonen-Aarnio (2010, 2014). And I agree with almost everything 
she says about the connection. The biggest difference between us is terminological. She uses 'reasonable' and 'reasonableness' where I use 'wise' and 'wisdom'. In my idiolect, I find it too easy to confuse 'rational' and 'reasonable'. So I'm using a different term, and one that, to me at least, more strongly suggests a focus on agents, not states. But this is a small point, and everything I say about the distinction draws heavily on Lasonen-Aarnio's work.

Finally, I'm not taking evidentialism to be committed to any kind of uniqueness thesis. It may be that different agents with the same evidence can have different views about $p$, and both be rational. That's fine, as long as any agent with just that evidence could have either view about $p$ and be rational. The view is that there's a function from evidence and attitude to rational evaluation, not that there's a function from evidence to rational attitude.

\section{Memory and Testimony}

It's natural to think about theories of memory by analogy to theories of testimony. Indeed, we see this strategy used in otherwise very different work by Sarah Moss (2012) and David James Barnett (2015). Moss and Barnett have very different views on memory, and very different views on the relationship between memory and testimony, but they both find it worthwhile to situate views about memory in relation to views about testimony. And I will follow this lead.

For an evidentialist, there are three interesting classes of theories of testimony. These almost, but not quite, track onto familiar categories of theories in the literature on testimony. I'll use slightly idiosyncratic names for them, just to indicate that the categories aren't exactly the same. In all cases, speaker $S$ says that $p$ on the basis of evidence $E$, and hearer $H$ hears (and understands) the speaker. (And I'll assume $S$ is a she, and $H$ a he.) I'm going to start with the case where $S$ knows that $p$, and $H$ has no reason to doubt $S$ 's testimony; we'll look at the complications that ensue when those assumptions are dropped presently.

The classes I'm interested in are divided by their answers to two questions:

1. Is the evidence that $H$ gets, in the first instance, that $p$, or that $S$ said that $p$ ?

2. If the evidence is only that $S$ said that $p$, is the fact that $S$ said that $p$ a 'self sufficient' reason to believe that $p$, or does it need to be supplemented?

The term 'self sufficient' is borrowed from Anna-Sara Malmgren (2006), who uses it in describing work by Crispin Wright (2002, 2004), James Pryor (2004) and Roger White (2005). Wright, Pryor and White are primarily concerned with whether perceptual appearances are self sufficient reasons to believe their contents, or they need to be supplemented. That isn't the focus here; like Malmgren I'm focussing on testimony and memory. 
Here are the three classes of views that you get from the natural answers to those questions.

Indirect Theories of Testimony. The evidence is that $S$ said that $p$, and this is not a self-sufficient reason to believe that $p$. This class closely corresponds to the class of so-called reductionist theories of testimony. Jennifer Lackey (2008) provides an important recent indirect theory.

Direct Theories of Testimony. The evidence is that $S$ said that $p$, and this is a self-sufficient (though defeasible) reason to believe that $p$. Many theorists who reject reductionism about testimony endorse what I'm calling a direct theory. C. A. J. Coady (1995) provides an important recent direct theory.

Transmission Theories of Testimony. The evidence is that $p$, so it doesn't matter how we answer the second question. Frederick Schmitt (2006) provides an important recent transmission theory.

Transmission theories need not deny that $H$ also gets the evidence that $S$ said that $p$. And they need not take a stand on how good that evidence is as evidence that $p$. And direct theories need not deny that $H$ may have independent evidence that if $S$ says that $p$, then $p$ is true. But in the other direction, I'm taking it as characteristic of the theories that they deny the core claims of the ones that come after them. So indirect theories deny that $H$ immediately gets evidence that $p$, or that $S$ says that $p$ is a self sufficient reason to believe $p$. And direct theories deny that $H$ immediately gets evidence that $p$.

The direct and transmission theories just say that a certain thing is possible. I haven't said yet what they have to say about when it possible. To make matters a little less abstract, I'll focus for now on theories that abide by the following constraints.

- $S$ saying that $p$ is only reason to believe that $p$ in the absence of evidence against $p$, and in the absence of evidence against $S$ 's reliability.

- $H$ only gets to add $p$ to their stock of evidence if it was in $S$ 's stock of evidence to start with; testimony doesn't generate evidence, except for evidence about what is said.

A direct theory that didn't comply with the first constraint really would be a charter for gullibility. Even with this constraint, direct theories possibly are too gullible, as Elizabeth Fricker (1994) has argued, but without this constraint they certainly are. And a transmission theory that didn't comply with the second constraint would not deserve the name transmission; it would be a generative theory.

We can use these categories to draw three similar categories of memory. Here the case is that $M$ forms a belief that $p$ at $t_{1}$, and has an apparent memory of $p$ at 
$t_{2}$. As we might put it, her memory reports that $p$ at this time. As above, start with the simple case where $M$ knows $p$ at $t_{1}$, and there is no counterevidence, or reason to doubt her own reliability, at later times. We'll come back, in great detail, to cases where those assumptions are relaxed. What evidence does $M$ get, in these simple cases, when her memory reports that $p$, and how good is this evidence?

Indirect Theories of Memory The evidence is that $M$ 's memory reports that $p$, and this is not a self sufficient reason to believe that $p$.

Direct Theories of Memory The evidence is that $M$ 's memory reports that $p$, and this is a self sufficient reason to believe that $p$.

Transmission Theories of Memory The evidence is that $p$.

The first two theories are temporally local, in the sense I started with, and the last is temporally extended. Again, we'll put some restrictions in place.

- Memory's reporting that $p$ is only a self sufficient reason to believe that $p$ in the absence of either evidence against $p$, or evidence that memory is unreliable.

- Memory only transmits evidence that $p$ if $p$ was genuinely among $M$ 's pieces of evidence at an earlier time. And that requires, I'm assuming, that $M$ knew that $p$ at the earlier time. ${ }^{2}$

Since I want to defend a temporally extended theory, that means I'm defending the transmission theory. And like Barnett, I do so while rejecting the corresponding theory of testimony. ${ }^{3}$ But once we set things out this way, we see that there are two distinct temporally local theories, and they fail for slightly different reasons. Before we get to why they fail, we'll look at a reason for thinking one or other of them must work.

\section{Shangri La}

The Shangri La case introduced by Frank Arntzenius (2003) can be used to generate an argument that evidentialists are committed to the temporally local approach to evidence. This isn't exactly how Arntzenius introduced it; he introduced it as a puzzle for conditionalisation. But the argument I'm interested in is related to the puzzle Arntzenius introduced. Here is how Michael Titelbaum describes the example.

\footnotetext{
${ }^{2}$ As with the transmissive view on testimony, I don't take it to be essential to the transmissive view that all mnemonic knowledge is transmitted. Perhaps, as Lackey (2005) argues, memory can sometimes generate new knowledge. Even so, as long as it sometimes plays a purely preservative role, the transmissive theory is true.

${ }^{3}$ Michael Dummett (1994) also defends a transmissive account of memory, though the analogy between testimony and memory is important in his argument. Jérôme Dokic (2001) endorses Dummett's position on memory.
} 
You have reached a fork in the road to Shangri La. The guardians of the tower will flip a fair coin to determine your path. If it comes up heads, you will travel the Path by the Mountains; if it comes up tails, you will travel the Path by the Sea. Once you reach Shangri La, if you have traveled the Path by the Sea the guardians will alter your memory so you remember having traveled the Path by the Mountains. If you travel the Path by the Mountains they will leave your memory intact. Either way, once in Shangri La you will remember having traveled the Path by the Mountains. The guardians explain this entire arrangement to you, you believe their words with certainty, they flip the coin, and you follow your path. What does ideal rationality require of your degree of belief in heads once you reach Shangri La. (Titelbaum, 2014, 120)

The name of the person Titelbaum's narrator is addressing isn't given, so we'll call him Hugh. And we'll focus on the case where Hugh actually travels by the Mountains.

\section{Arrive in Shangri La}

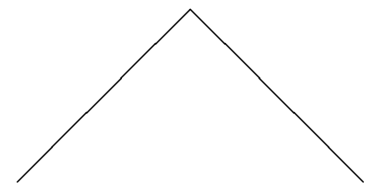

Travel by sea Travel by

Then memories replaced mountains

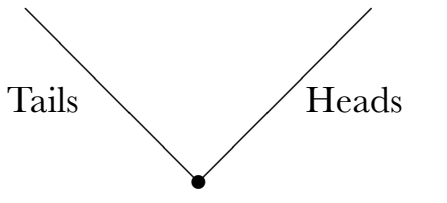

Figure 1.1: Original Shangri La game; Hugh takes the right-hand path

There is something very puzzling about Hugh's case. On the one hand many philosophers (including Arntzenius and Titelbaum) report a strong intuition that once in Shangri La, Hugh should have equal confidence that he came by the mountains as that he came by the sea. On the other hand, it's hard to tell a dynamic story that makes sense of that. When he is on the Path by the Mountans, Hugh clearly knows that he is on that path. It isn't part of the story that the paths are so confusingly marked that it is hard to tell which one one is on. Then Hugh gets to Shangri La and, well, nothing happens. The most straightforward dynamic story 
about Hugh's credences would suggest that, unless something happens, he should simply retain his certainty that he was on the Path by the Mountains.

And you might think evidentialism is committed to the same thing as that dynamic story. To see why, imagine that Hugh is being terrifically sneaky, and wearing a small camera in his glasses. The camera is tracking what he sees, and Laurie is watching it on a distant TV monitor. The guardians can't do anything to Laurie's memory, so they don't, just like they don't do anything to Hugh. That night, it might seem Hugh and Laurie have the same evidence. Yet, according to some intuitions, it is rational for Laurie to believe that Hugh took the Path by the Mountains, and not rational for Hugh to believe this.

Here's a natural way out of that bind. Say that the evidence Hugh and Laurie have does not consist of what they saw as Hugh was ascending, but their current mnemonic seemings. Now their evidence is different. Hugh has the evidence that it seems to Hugh that Hugh ascended via the mountains, and Laurie has the evidence that it seems to Laurie that Hugh ascended via the mountains. And it is common knowledge that in either this world or a nearby one, Hugh's mnemonic seemings are unreliable, while Laurie's are reliable in all nearby worlds. So the temporally local theories can handle the problem, while one might think temporally extended theories cannot.

The most straightforward way to explain the common intuition about Shangri $\mathrm{La}$ is via the indirect theory of memory. On that theory, Hugh won't know that he came to Shangri La via the mountains. That's because the report of his memory, "We got here via the mountains, Hugh!", would be the same however he came up, and Hugh knows it. There is no basic entitlement, on this theory, to move from My memory says that $p$ to $p$, and since Hugh does not even believe that a correlation obtains in practice between what he believes about his method of ascent and how he actually ascended, there is no earned entitlement.

It is a little tempting to read some of the published arguments that Hugh can't know he came via the mountains as reasoning in just this way. Here is Arntzenius's central argument. (Assume Arntzenius is talking to Hugh here, so 'you' picks out Hugh.)

For you will know that he would have had the memories that you have either way, and hence you know that the only relevant information that you have is that the coin was fair. (Arntzenius, 2003, 356)

Sarah Moss (2012) makes a similar claim about the case. (Again, her narration is addressed to Hugh.) 
Intuitively, even if you travel on the mountain path, you should have .5 credence when you gets to Shangri La that the coin landed heads. This is a case of abnormal updating: once you arrive in Shangri La, you can no longer be sure that you traveled on the mountain path, because you can no longer trust your apparent memory. (Moss, 2012, 241-2)

Now it isn't immediately clear why the fact that Hugh would have the same apparent memories in the two cases should matter. As far as I can see, the only way it could matter is if the following two things were true. First, we are using a temporally local theory, so the evidence is what Hugh's memory reports when he is in Shangri La, not the evidence he acquired on the trip up the mountain. And second, what those appearances support is solely a function of things internal to the agent, and not, say, their connection to the truth. As an evidentialist, I'm committed to a version of that second assumption - at least, I'm committed to saying that things that over-ride evidence must themselves be evidence.

Let's focus for now on the assumption of temporal localism behind the arguments here. I'm going to offer a series of arguments against it, starting with a variant on the Shangri La case.

\section{Iterated Shangri La}

Here's a slightly more complicated variant of the Shangri La example.

Sati walks up to the base of the paths to Shangri La. "Have some toast and yeast extract," says one of the attendants, somewhat stiltedly.

"Yeast extract?" says Sati.

"Yes, yeast extract. Vegemite or Marmite, your choice.".

"Must I?" says Sati.

"You must."

"Well, Vegemite then," says Sati, recalling fond memories of having Vegemite in Australia, and dire memories of that trip to the English countryside.

"Good choice," says the attendant. Sati has her Vegemite on toast, and heads up the mountain path to Shangri La, as directed. On the way, she notices a worried looking person standing in front of a priest about to flip a coin. When she gets to Shangri La, she asks the attendant about that.

"Oh," says the attendant, "he chose Marmite." Sati looks confused as to why this is relevant, so the attendant continues. "The priests don't 
like people who choose Marmite, but they still must let them through. So they flip a coin to decide whether they will go by the sea or the mountains. Then, if they went by the sea, they will wipe the memory of that trip, and replace it with a memory of going through the mountains."

"I'm glad that didn't happen to me. Lucky I chose Vegemite."

"Recently," continued the attendant, "the priests decided to make things more complicated. They decided they would also wipe the memory of having eaten the Marmite, and hence facing the coin flip. Instead they would implant a false memory of having chosen Vegemite, indeed false memories of having preferred Vegemite to Marmite in the past, plus a false memory of seeing some other poor sap facing the coin flip. They really really don't like Marmite eaters."

"So all the Marmite eaters get memories wiped?" asked Sati.

"No, only if the coin lands the wrong way. So some people get to the top thinking they liked Marmite. But we only tell that memories of going by the sea will be wiped. In fact, knowing they chose Marmite is evidence they went by the Mountains, but they don't know that."

"It all sounds horrible," says Sati. "I'm so glad I remembered I liked Vegemite more than Marmite."

"Have a good day!" said the attendant, grinning.

I think that Sati's last statement is correct; she does remember that she likes Vegemite more than Marmite. Indeed, she knows this in virtue of her memory. But it's not clear how a temporally local theory, either direct or indirect, can get that answer.

Imagine someone, call him Joe, who starts off in the same situation as Sati at the base of the mountain. Sadly, due to an unfortunate unbringing, he prefers Marmite to Vegemite, so he takes that. And then the coin lands the wrong way, and he is sent by the sea. Then his memories are wiped and replaced with fake memories when he gets to Shangri La.

If a temporally local theory is correct, then presumably Sati and Joe have the same evidence. And that means if evidentialism is true, then it is rational for them to believe the same things. Yet that is implausible; Joe should not be very confident that he had the Vegemite, came by the mountains, and so on.

On the other hand, it is overdetermined that Sati can know she came by the Mountains. The crucial difference between Sati and Hugh comes from the defeasibility conditions on the transmission theory. Past memories that $p$ transform into current evidence that $p$ unless they are forgotten, or the agent gets some good reason to suspect that her memory is unreliable. Hugh has such a reason; he is a coin flip 
Arrive in Shangri La

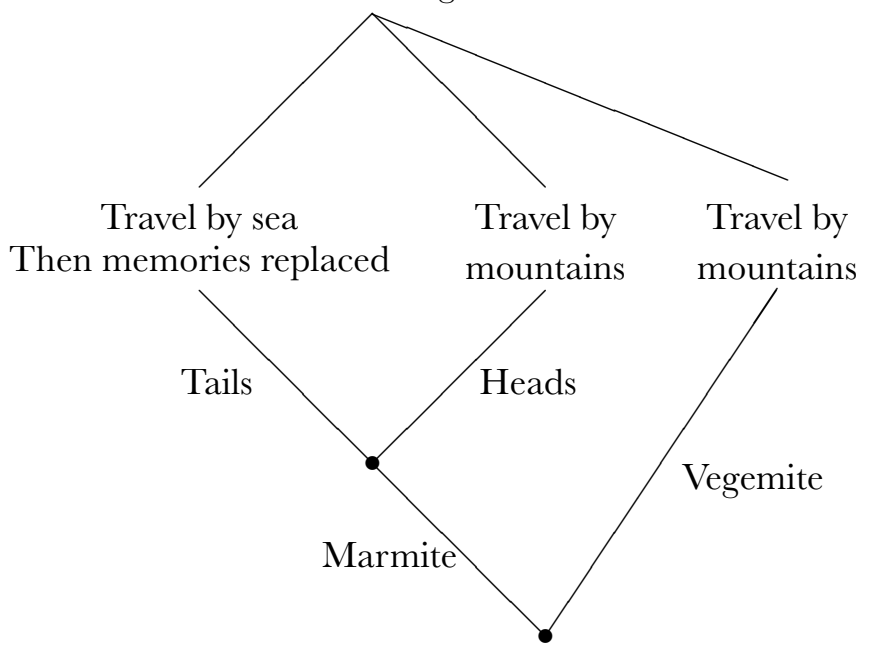

Figure 1.2: Revised Shangri La game; Sati takes the right-hand path, Joe the lefthand path

away from having faulty memories. Sati does not have such a reason. She knows that had she had a very different kind of upbringing, and had she been on the bad end of a coin flip, she would have had faulty memories. But a reason to think that had things been different she would have reason to distrust her memories is not, itself, a reason to distrust her memories.

Sati's case is not meant to be a close call. There are lots of relevant ways in which her case is different to cases in which the defeasibility clause is triggered. The fact that two different kinds of things need to have gone wrong here is relevant. And the fact that the first requires things going wrong for a long long time into the past is relevant. And the fact that the first is only a problem in very different possible worlds to actuality is relevant. In short, any plausible kind of defeasibility condition whatsoever on the transmission theory will mean that Joe's memories of going by the sea are not transmitted, but only an implausibly strong defeasibility condition will prevent Sati's memories from being transmitted.

Note that I have not said that Sati can trust her memories because the probability of them being unreliable is so low. That is not the way to formulate defeasibility conditions. The sense of probability that is relevant here is evidential probability. And evidential probability is, as the name suggests, explanatorily posterior to evidence possession. We should not use evidential probability in our theory of what 
evidence the agent has. Sati knows she grew up liking Vegemite, despite the Shangri La shenanigans. But that's not because it is so improbable that she had her memories wiped. Rather, it is improbable she had her memories wiped because she knows she does not meet the conditions under which memories are wiped.

So temporally extended theories can distinguish Sati's case from Joe's, as intuition requires that they be distinguished. But temporally local theories seem to have a problem here. Perhaps the problem here is not with the theory of mnemonic evidence that the the temporally local theories hold, but with evidentialism. Perhaps, that is, this is a case where we should say that Sati and Joe have the same evidence, but that this evidence supports different beliefs given the different reliability of their memories.

But there is little to be said to motivate such a theory. If we aren't going to be evidentialists, it isn't clear what the relevance of a theory of evidence is. And if we are going to say that historical events, like the fact that Joe's memories were wiped and Sati's weren't, are relevant to contemporary rationality, it isn't clear what we gain by having a temporally local theory of evidence. Either way, we have said that the existence of past events is relevant to the rationality of current beliefs. At this point we aren't engaged in much more than a terminological dispute with the temporally extended theories.

\section{Against Indirect Theory}

As Matthias Steup (2013) argues, the indirect theory of memory is implausible. It says that when one remembers that, say, the Chicago White Sox won the 2005 World Series, there are two things that are needed in order to ground the rational belief. The first is the apparent memory, and the second is some kind of reason to think that the memories are reliable. But the only reasons we could have for believing the second comes from what we have learned about the track record of memory, or perhaps of the role of memory in human functioning. And we couldn't be rational in believing those things unless we could rationally rely on memory in forming beliefs. So we can never rationally form any belief on the basis of memory unless we antecedently have reason to trust memory. And that, plus the indirect theory of memory, leads to a vicious regress, and hence to an implausible scepticism.

The argument here is similar in form to an argument that has often been levelled against the indirect theory of testimony. This argument traces back at least to Coady (1995). The argument is that children can rely on testimony to get knowledge, and hence rational belief, but they don't have the information or the cognitive capacity to rationally judge who is and isn't reliable. So it can't be, contra the indirect theorist, that such judgments of reliability are required in order to get rational belief and knowledge from testimony. 
One problem with such an argument in the case of testimony is that it has relied, historically, on a very impoverished view of the cognitive capacities of young children. It is true that the capacity shown for explicit reasoning by children is often very weak. But they have rather amazing capacities for implicit reasoning, and there isn't any reason to think they could not judge and track reliability of informants. ${ }^{4}$

The issue here is not capacity, it is information. No matter how much capacity you have, you can't make rational judgments about the reliability of memory without information about memory. And you can't have that information without being able to use memory. That's the key problem.

We can use this idea to strengthen the arguments in the previous section about Sati. If the indirect theory of memory is wrong, we have to be a bit careful about why Hugh can't know he came by the mountain path. It can't just be that he lacks a reason to think his memories are reliable. Rather, it must be that what he was told at the bottom of the mountain is a reason to think his memories are not reliable. It must be the presence of reasons to doubt memory, not the absence of reasons to trust, that is doing the work.

And, as noted, this is a big difference between Hugh's case and Sati's. Sati does not have any positive reason to doubt her memory. She is several steps removed from the situation where her memories would be in doubt. It's true that her mnemonic beliefs are insensitive to the truth in a certain way. Arguably, the nearest world in which she came to Shangri La by the sea is one where she still believes she came by the mountains. But any kind of defeasible, direct theory of memory will allow for some rational but insensitive belief.

Assume that our theory says that $S$ can rationally use her memory to believe that $p$ unless defeaters $D$ are triggered. And $S$ uses her memory to (accurately) remember $\neg D$. That is, she remembers that she is not in a situation where those defeaters are triggered. Presumably if $D$ were true, her memory would be unreliable; that's what makes $D$ a defeater. So there isn't any reason to think that this mnemonic belief in $\neg D$ is sensitive; she may well still have had it were $D$ true. But the direct theory implies this doesn't matter, and the direct theory is the only theory on the table given that the indirect theory leads to implausible scepticism.

Could it be that Sati should not trust her memory because she is, and she knows she is, in a class of people whose memories are unreliable? Well, the mere fact that she is in such a class is not interesting. She knows, after all she is a member of the

\footnotetext{
${ }^{4}$ On children's capacities to learn, see Saffran et al. (1996a,b) and Gopnik et al. (2001). For applications of this directly to the judgments of credibility, see among many others, Koenig et al. (2004) and Harris and Corriveau (2011). Jaswal et al. (2008) show that children don't just track credibility of informants, they trade off credibility of informant against credibility of what is currently being said. In general, the lesson from the last 10 to 20 years of research is that children have more than enough capacity to perform the cognitive tasks that indirect theorists require of them.
} 
class consisting of her and all people with unreliable memories, and the memories of that class are as a group unreliable. But that's not a reason to distrust her memory. Or, at least, it can't be on pain of scepticism. What must matter is that she is in such a class, and it is epistemologically significant. But the significant class around here seems to be the class of people whose memories have been erased, or who have reason to suspect their memories have been erased. And that doesn't include Sati. She knows she likes Vegemite, and has for a long time, and she knows that only Marmite-likers in Shangri La had their memories erased.

Here's what is true of Sati. She is, right now, phenomenally indistinguishable from a possible person whose memories are unreliable. But why should that matter? We all know brain in vat cases are possible, and each of us is phenomenally indistinguishable from such an unreliable 'person'. But that isn't on its own grounds for doubt about memory. All that she learns from the attendant is that another kind of brain in vat case is possible. But she knew they were possible all along. The case isn't actual and, unless we come up with a trigger for the defeater in the theory of memory, she has no reason to think it is actual.

\section{Argument from A Priority}

There is another argument against the temporally local theories, and against both the direct and indirect theories, that we can derive from the work of Tyler Burge (1993, 1997). (I should note that there is considerable dispute about how best to interpret Burge. I'm not claiming that what follows is the best interpretation, or the only interpretation, just that it is an interesting argument inspired by, and quite arguably contained in, his work.)

Tamati is doing a proof. At one stage in the proof he appeals to Fermat's Little Theorem, which says for any natural number $n$, and any prime $p, n^{p} \equiv n(\bmod p)$. Using this theorem, Tamati completes his proof, and derives a nice result $M$. Intuitively, Tamati has not just come to know $M$, but he has come to know $M$ a priori.

But assume, now, that either kind of temporally local theory is true. At one stage of the proof, Tamati had to, at least implicitly, reason as follows. It seems to me that I remember that $n^{p} \equiv n(\bmod p)$, so (perhaps with an extra premise), $n^{p} \equiv$ $n(\bmod p)$. And that can't be a priori reasoning, since the premise about how things seem to Tamati is contingent and a posteriori. If the indirect theory of memory is right, the extra premise needed about the reliability of Tamati's memory will also be contingent and a posteriori.

It would be a very strange and revisionary theory of the a priori to say that any proof is not a priori if it relies on remembered theorems without, perhaps, memory of the proof of that theorem. The proof of Fermat's Little Theorem isn't difficult, but it does go through several steps. It is hard to keep the whole proof in mind at 
once. Even proving it, that is, requires a little memory. On the temporally local theory, it isn't clear that it could ever be a priori knowable for any normal person. And any theorem that required using it would similarly be a posteriori.

Perhaps it could be said that Tamati's reasoning is a priori because it doesn't rely on sense perception, only on perception of how things seem to Tamati. But some such perception of how things seem yields a posteriori knowledge. If Tamati has a headache, and notices this at the same time he remembers Fermat's Little Theorem, he gets a posteriori knowledge of the contingent truth that he has a headache, and a priori knowledge of the necessary truth of the theorem.

In short, a transmissive theory of memory is required to get the result that Tamati gets a priori knowledge of the mathematical theorem. As Burge argues, a transmissive theory of testimony gets the exciting result that when Tamati goes on to tell his friend about $M$, the friend gets a priori knowledge of $M$ as well. If one thinks it is intuitive that the friend's knowledge is a priori, that's a good reason to favour a transmissive view of testimony. But that the friend's knowledge is a priori is not as intuitively obvious as that Tamati's knowledge is a priori, so it isn't obvious we must treat memory and testimony the same way here.

I'll end this section with a note about the dialectic. What would the argument of the paper lose if the arguments of this section didn't work? This is an important question because of arguments, such as those by Daniele Sgaravatti (2012, Ch. 3), that the a priori/a posteriori distinction can't do the epistemological work that it is traditionally taken to do. The answer is that we'd lose one of the best arguments against the direct version of the temporally local theory, while the argument against the indirect version would not be significantly affected.

Assume for now that one is happy with Tamati's knowledge, and indeed all nontrivial mathematical knowledge, being a posteriori in this way, because it relies on mnemonic knowledge about one's earlier self. There is still the question of how one gets from this knowledge about one's earlier self to knowledge of mathematics. On this indirect theory, this goes via reasoning about the reliability of one's earlier self. But that reasoning will have to use some non-trivial mathematics, and we'll be back in the kind of circle we warned about in the previous section. On the direct theory, this won't be a problem, since there isn't any challenge in getting from I have an apparent memory that $p$ to $p$. That inference is perfectly sound, as long as one lacks reasons to distrust it. It is still, I think, puzzling that we have to analyse mathematicians as reasoning this way, and generating a posteriori knowledge. But they key dialectical point is that sense of puzzlement is only relevant to thinking about the direct version of the temporally local theory; the indirect version is beset by a host of further and more serious problems. 


\section{Argument from Laundering}

The arguments involving Sati and Tamati were designed to show that not all rational mnemonic belief relies on inference from the existence of a current mnemonic seeming. But neither argument suggested that there was anything wrong with such inferences. It is fully compatible with what I said about both Sati and Tamati that they could also try to infer from how things seem to them to facts about how they got to Shangri La, or about modular arithmetic.

Barnett's argument for a temporally extended view takes the opposite tack. He thinks there is something problematic about these inferences, or at least a special class of them. And because of this, he infers that the inference from present seeming can't be explanatorily important. And that gets him to a version of a temporally extended theory.

So what's the problem? Here's the schematic case that he focusses on.

Two Beliefs On Monday you came to believe that $p$ for good reasons that justified your belief, and on Tuesday you came to believe that $q$ for bad reasons that failed to justify it (where $p$ and $q$ are independent). It is now Wednesday, and you have forgotten nothing, reconsidered nothing, and learned no new relevant evidence. You recall each conclusion without occurrently recalling your original reasons for those conclusions. (Barnett, 2015, 15)

Again, it's a bit of an annoyance to use 'you', especially since you, dear reader, would not do anything so foolhardy as come to believe $q$. So let's assume Barnett's narration is directed at Kim. And the question is, is Kim's belief that q, on Wednesday, rational? Assume, to make the case most interesting, that this mistaken inference to $q$ is completely out of character. Kim is, and knows he is, a very reliable processor of information, who rarely makes this kind of mistake.

The worry is that any temporally local theory will say that Kim's belief on Wednesday is rational. After all, Kim has an apparent belief that $q$, and not only lacks evidence of his unreliability, but knows he is reliable. Great! But, intuitively, his belief doesn't go from being irrational to being rational just by the passage of time. It can't get its irrationality laundered out in this way.

But it isn't clear how big a problem this really should be. Note that Kim is supposed to have forgotten nothing. So the evidence on which $q$ was based is still there. Now allow the temporally local theory a principle that they should want on independent grounds. That principle is that evidence screens judgment; the evidential force of the fact that an agent made a judgment is completely screened, for 
that agent, by the evidence the judgment was based on. ${ }^{5}$ I just stated that principle sychronically, so it doesn't immediately have implications for Kim's case. But it is plausible to say that as long as the judgment remains, its evidential force is screened off by the evidence it was based on.

Now whether one has a direct or indirect theory, Kim is not obviously compelled to hold on to her belief that $q$. And whether or not one believes the screening principle, the fact that Kim has forgotten nothing means that there is no symmetry between the cases of $p$ and $q$. The relevant evidence is different in the two cases. The only theorist who has a challenge here is one who thinks that only occurrent states are evidence, and that is a particularly implausible addition to the indirect theory.

Barnett's case is different in a couple of respects than an example Gilbert Harman (1986, Ch. 4) uses to draw rather different conclusions. Working through the differences between them allows us to see something interesting about rational dilemmas, even if it isn't immediately relevant to the debates about memory.

In Harman's example, Karen first draws a conclusion $q$. This is actually rational for her to draw given her evidence, but her evidence was extremely misleading. She then forgets why she came to believe $q$, and gets new evidence that would show her the old evidence was misleading. But since she doesn't remember why she believed $q$, she doesn't know that this new evidence affects her grounds for belief in $q$, and retains the belief.

Harman says that this is rational. Karen isn't required to keep track of her evidence for each thing she believes. That seems right. It is hardly a rational failing of mine to not remember precisely why I think that the White Sox won the 2005 World Series; I don't need to keep that level of detail in mind. And if Karen does not do that, she can't be expected to adjust her beliefs when the evidence that, unbeknownst to her, they are based on is undermined.

Harman thinks that our original intuition about Karen's case is that her belief in $q$ is irrational once it has been undermined. But he also thinks reflection on real life cases like Karen's shows this intuition to be mistaken. The lesson he draws from this is that something like the direct theory is right; Karen can trust her memories unless she has a special reason to doubt them, even if in fact she couldn't put together a positive argument for their reliability.

Barnett's case of Kim is different than Harman's case of Karen in two respects. Kim retains his evidence; Karen loses hers. And Kim makes an irrational mistake; Karen is rationally misled by misleading evidence. Are those differences enough to

${ }^{5}$ I haven't actually defended this in print yet, but it is correctly attributed to me by Sophie Horowitz $(2013,25)$. 
think we should treat the cases differently? Or should we be worried that Karen's case, like perhaps Kim's, is one where intuition is not a reliable guide?

I don't actually have a firm view on this. The differences are significant. Harman himself thinks that the intuition in Karen's case is driven by the mistaken assumption that Karen will track and retain her evidence. That's not true in normal cases like Karen's. But it is true, by stipulation, in Kim's. So that is one big reason for treating the cases differently. Still, I do worry a little that we're drifting into areas where intuition is unreliable.

To make that worry a little more concrete, consider this argument for the conclusion that Kim's belief in $q$ is actually rational.

1. It would be irrational for Kim to re-open inquiry into whether $q$, given that it was settled, and no new evidence has come in.

2. It would be irrational or impossible for Kim to intentionally forget $q$.

3. Kim cannot change his attitude to $q$ without either re-opening inquiry into whether $q$, or by forgetting $q$.

4. There is some rational attitude towards $q$ that Kim can take.

5. So, Kim is rational to retain belief in $q$, since any other possible path would involve irrationality of some kind.

Premises 2 and 3 aren't, I think, particularly controversial, especially if 'inquiry' is read so broadly that any re-evaluation of $q$ counts as re-opening inquiry. The issues are premises 1 and 4 . Premise 4 is a no dilemmas principle. We'll return to it later, though in this context it is notable that Barnett himself endorses it, as do many other epistemologists. (Barnett, 2015, 10)

The big issue is premise 1. I think it is true. It is a mistake to go around constantly reconsidering things that one has settled. Once a decision has been reached, it should be held, unless a reason comes along to reconsider it. That reason may be evidence that the decision was faulty, or reason to think the decision was badly made. But the mere passage of time is not a reason to reconsider, and nor is the fact that if inquiry were (properly) conducted, it would yield a different conclusion.

The picture I'm putting forward here owes a lot to Richard Holton (1999, 2009, 2014), as well as to a related idea due to Crispin Wright (2004). Holton argues that if one has an intention, rationality requires one to maintain that unless a good reason comes along to reconsider it. The fact that one would not form the intention again were one to reconsider it is not, he thinks, itself a good reason. Strikingly, he says that even in Kavka's toxin puzzle (Kavka, 1983), the agent who intends to drink the toxin should not reconsider, because they have no reason to do so. (Holton, 2009, 162-5). And he suggests that we should think of belief along similar lines (Holton, 2014). To believe something is to commit to its truth, and we need a positive reason 
to give up our commitments. Wright argues that the sceptic tries to lure us into opening inquiries we can tell will not be completed. We should resist the lure. We have no reason to open the broad ranging inquiry into our own competencies that the sceptic wants us to hold, and good reason to avoid it. ${ }^{6}$

We can perhaps motivate the application of these ideas to cases like Kim's by thinking of a similar case involving action.

Ned has been thinking about buying a new bed. He is deciding between a wood bed and a metal bed. And he just decided to get the wood bed. This is a bad mistake. He will like the metal bed much better, and this is in fact clear from the evidence available to Ned. But he's made up his mind. The wood bed store is five miles east, the metal bed store is five miles west. And there's Ned in his car, driving eastward. What does rationality require of Ned now?

I think Ned's in a rational dilemma. It is irrational to drive to the wood bed store and buy a wood bed. He won't like it, and it is predictable that he won't. What a mistake. But it is irrational to reopen inquiry. He's made up his mind, and now he should focus on the road. He hasn't received any new evidence about the qualities of the bed, or any reason to think he mis-evaluated the old evidence. And we can't go around second guessing our past decisions all the time. That includes those of us (presumably all of us) who make mistakes. It is irrational to be fickle.

So what can Ned rationally do? The arguments of the previous paragraph suggest he's in a rational dilemma. If you want to act rationally, you shouldn't start where Ned is. If he keeps driving to the wood bed store, he'll irrationally buy a sub-optimal bed. If he thinks again about the issue, he'll be irrationally fickle. Rationality requires something that is practically impossible; changing his mind about what to buy without re-opening the issue of what to buy.

This is a dilemma for Ned, but it is one he could have avoided. He could have not made the mistaken decision in the first place. It may or may not be unfair if rationality makes incompatible demands on an agent without any chance to avoid them. But it isn't unfair to think that agents who make mistakes at $t_{1}$ are, in virtue of those mistakes, left without any good options at $t_{2}$. Mistakes have consequences.

\footnotetext{
${ }^{6}$ Sue Hamilton $(2001,78)$ says that this idea, that it is wrong to open an inquiry you know you can't complete, plays a central role in the epistemology of the important Nyāya philosopher Gotama. The discussion of forecasting in Tetlock and Gardner (2015) might cast doubt on whether the kind of conservatism I'm endorsing here is empirically sound. There is a suggestion there that people who tinker with their credal states more frequently end up with more accurate credences. This is a topic that deserves revisiting as more data comes in.
} 
Is this inconsistent with evidentialism? I said above that evidentialism says the rational status of a belief supervenes on the evidence that the agent has. Yet now I'm saying Ned is irrational to change his mind. But if he had, with the very same evidence, believed that he should get the metal bed, that would have been rational. This looks like a counterexample to evidentialism.

Here's why it isn't a counterexample. What is irrational for Ned is re-opening inquiry into what bed to get. It is the activity of engaging in further consideration of the question that it is irrational. Moreover, this is irrational because the evidence that is available to make this decision does not support it. Should Ned irrationally engage in this activity, there is a uniquely rational way to finish it, which is to change his mind. But that's not the same as saying that he should, rationally, change his mind.

I am making a big assumption here, but one I think is true. Careful consideration involves thinking through a large amount of evidence. Decisions to engage in careful consideration must be made on the basis of flimsier amounts of evidence. After all, to bring all the evidence one has to bear on a question is to engage in careful consideration. So a decision to engage in such consideration must not use all that evidence. So evidentialism must say that the rationality of a belief, credence, decision etc must depend on, i.e., supervene on, the evidence available to the agent when they make that decision. And when deciding whether to carefully consider or reflect on the evidence, very little is available.

That's why I think Ned isn't a counterexample to evidentialism. And nor is Kim a counterexample to evidentialism, even if there is no way she can rationally lose her belief in $q$. For Kim too faces a dilemma, of just the same kind. So the argument I gave for the rationality of Kim's continuing to believe $q$ goes wrong at step 4 . Kim has gotten herself into a mess, and there are no rational ways out.

But note that last conclusion cuts across the theories of memory we've considered here. The temporally extended theory has, as its distinctive claim, that some agents have a kind of evidence that the temporally local theory says no agent has. But Kim is not one of those agents. The evidence in question is evidence one gets when one acquires a piece of knowledge, and keeps that token mental state across time. And the relevant fact about Kim is that he has a belief in $q$ that is well and truly not a piece of knowledge. So it doesn't look like the case should tell the local and extended theories apart.

What it does so is show that there is a new kind of argument for the possibility of rational dilemmas. People make mistakes. When they do, there might be no good way to undo the effect of the mistake. And then they're in a dilemma. We don't avoid that conclusion by giving people who don't make mistakes more evidence. 


\section{Conclusion and Future Research}

I've argued for a transmissive, temporally extended, view of memory and the evidence it provides. When I remember that the White Sox won in 2005, it is the fact that they won which is my evidence, not my apparent memory. The role of memory is to preserve this fact in evidence, not to give me new evidence for it. Saying this invites any number of questions. I'll end with a list of several ones that I find fascinating, but which I'm a long way from having answers to, divided up loosely into questions about metaphysics, and questions about epistemology.

\subsection{Preservation}

What is it for memory to preserve a belief? Sven Bernecker (2008) has written on this at length, and the issue turns out to be much more complicated than we might first suspect. I'm particularly unsure about cases like this one,

Ankati. I haven't had to change planes at O'Hare for over five years. That makes me happy.

Bojan. Are you sure? What about the trip to Vancouver? Or the one to Hong Kong?

Ankati. Vancouver was a direct flight. And I went to Hong Kong via New York. But, oh, you're right, I came back via O'Hare. Sad face.

At the end Ankati remembers that she flew home from Hong Kong via O'Hare. Is this a belief that was stored in memory ever since it happened? If so, we have to say that Ankati had inconsistent beliefs at the start of the conversation. If not, then I think it is hard to say that the relevant evidence for the belief that saddens her is the fact that she transferred at O'Hare. In such a case, it seems to me that the temporally local theory is more plausible than in more usual cases.

\subsection{Initial Evidence and Over-Riding}

The following two questions are related:

- What past states can constitute present evidence?

- What present states can over-ride, or defeat, past evidence?

My instinct is to defend an extremely restricted answer to this pair of questions. In particular, $S_{\mathrm{S}}$ attitude towards $p$ at $t_{1}$ can only be evidence for her at $t_{2}$ if the following conditions obtain.

1. $S$ knows that $p$ at $t_{1}$. 
2. $S$ does not receive a significant amount of evidence against $p$ between $t_{1}$ and $t_{2}$.

3. $S$ does not receive (undefeated) reasons to distrust her ability to preserve information between $t_{1}$ and $t_{2}$.

But every one of these points is problematic.

The first point might imply some counterintuitive things about people who trust misleading evidence, such as 'Karen' in the earlier cited example by Gilbert Harman (1986, Ch. 4). Let's focus on an even simpler case than Harman's. Unlike me, my doppleganger Nairb believes that the Astros beat the White Sox in the 2005 World Series. That's because his web browser had been hacked on that crucial October morning, and it reported the wrong results. He hasn't seen any relevant evidence since. He has forgotten why he thinks the Astros won in 2005, but has held on to the belief. Is this belief rational, and what's his evidence for it?

The evidence can't be that the Astros won in 2005; they didn't. And it can't be that his computer reported that; he's forgotten that fact. Let's say that it is his apparent memory that they won, which seems to be the only remaining option. That would mean that the rationality of his forming the belief in the first place is independent of whether his current belief that the Astros won is rational. That's better than the alternative options, but it isn't particularly happy either.

The second point leads us into the version of the dogmatism puzzle that Maria [Lasonen-Aarnio2014a; has developed. Assume that significant evidence can factor into insignificant parts. Pazu knows that $p$, then gets three pieces of evidence $e_{1}, e_{2}$ and $e_{3}$ that tell against $p$. The conjunction is significant evidence, the individual parts are not. But the parts come in sequentially. When $e_{1}$ comes in, Pazu still knows $p$; after all, it is insignificant evidence. So Pazu can conclude, i.e., know, that it is misleading evidence. And, intuitively, we can ignore evidence we know to be misleading. So he ignores $e_{1}$. And for similar reasons he ignores $e_{2}$. Then $e_{3}$ comes in. Should he still ignore it? Presumably; it is on its own insignificant, and the only other evidence was known to be misleading, and so ignored. But it is odd that Pazu can hold onto his knowledge in $p$ in the face of these three pieces of evidence, while he would have lost knowledge had they come in at once.

Finally, we need to explain why evidence of unreliability of mnemonic processes can block mnemonic knowledge. If memory was a source of evidence, rather than a preserver of evidence, that would be an easy problem. In general, a source does not provide evidence to an agent if the agent has reason to believe that it is unreliable. The problem is how to motivate an extension of that principle to memory, which is in general not a source of evidence, but a preserver of it.

We could simply insist that the Shangri La case shows that the preservative role of memory can be defeated given sufficient grounds to doubt its accuracy. I think 
that's right, we can insist that. But there is a puzzle still about why this should be so. And that puzzle remains work for another day, as do the other puzzles in this section.

\subsection{Externalism}

Finally, there are some tantalising possibilities for new angles into familiar epistemological debates between internalists and externalists. It is hardly news that this is possible; Goldman's 'problem of forgotten evidence' is a familiar challenge to (certain) internalists (Goldman, 1999). But there might be other ways to make memory relevant to familiar debates.

If the temporally extended theory is true, then what is rational depends on something that is, well, extended. And if what is rational depends on something that is extended in time, we might think it is less surprising that is also depends on something that is extended in space. And that suggests the way to a kind of externalism.

We can do a bit better than that hand-waving metaphor though. There are versions of the New Evil Demon problem for transmissivism. If transmissivism is true anyway, that means those problems have solutions. Then we just have to find what those solutions are, and see if they generalise to solutions to the spatial version of the New Evil Demon problem. And if they do, we might have new ways to defend externalist theories of rationality, or at least new motivations for familiar ways to defend those theories.

\section{References}

Arntzenius, Frank. 2003. "Some Problems for Conditionalization and Reflection." Journal of Philosophy 100:356-370.

Barnett, David James. 2015. "Is Memory Merely Testimony from One's Former Self?" Philosophical Review Forthcoming.

Bernecker, Sven. 2008. The Metaphysics of Memory. New York: Springer.

Burge, Tyler. 1993. "Content Preservation." Philosophical Review 102:457-488.

—. 1997. "Interlocution, Perception, and Memory." Philosophical Studies 86:21-47.

Coady, C. A. J. 1995. Testimony: A Philosophical Study. Oxford: Clarendon Press.

Dokic, Jérôme. 2001. "Is Memory Purely Preservative?" In Christoph Hoerl and Teresa McCormack (eds.), Time and Memory. Issues in Philosophy and Psychology, 213-232. Oxford: Oxford University Press.

Dummett, Michael. 1994. "Testimony and Memory." In A. Chakrabarti and B. K. Matilal (eds.), Knowing from Words, 1-23. Dordrecht: Kluwer. 
Fricker, Elizabeth. 1994. "Against Gullibility." In A. Chakrabarti and B. K. Matilal (eds.), Knowing from Words, 125-161. Dordrecht: Kluwer.

Goldman, Alvin. 1999. “Internalism Exposed.” Journal of Philosophy 96:271-293.

Gopnik, Alison, Sobel, David M., Schulz, Laura E., and Glymour, Clark. 2001. "Causal Learning Mechanisms in Very Young Children: Two-, Three-, and FourYear-Olds Infer Causal Relations From Patterns of Variation and Covariation." Developmental Psychology 37:620-629, doi:10.1037//0012-1649.37.5.620.

Hamilton, Sue. 2001. Indian Philosophy: A Very Short Introduction. Oxford: Oxford University Press.

Harman, Gilbert. 1986. Change in View. Cambridge, MA: Bradford.

Harris, Paul L. and Corriveau, Kathleen H. 2011. "Young Children's Selective Trust in Informants." Philosophical Transactions of the Royal Society B 366:1179-1187, doi: 10.1098/rstb.2010.0321.

Holton, Richard. 1999. "Intention and Weakness of Will." The Journal of Philosophy 96:241-262.

—. 2009. Willing, Wanting, Waiting. Oxford: Oxford University Press.

—. 2014. "Intention as a Model for Belief." In Manuel Vargas and Gideon Yaffe (eds.), Rational and Social Agency: Essays on the Philosophy of Michael Bratman, 12-37. Oxford: Oxford University Press.

Horowitz, Sophie. 2013. "Epistemic Akrasia." Noûs Early View:1-30?, doi:10.1111/nous. 12026 .

Jaswal, Vikram K., McKercher, David A., and VanderBorght, Mieke. 2008. "Limitations on Reliability: Regularity Rules in the English Plural and Past Tense." Child Development 79:750-760.

Kavka, Gregory S. 1983. "The Toxin Puzzle.” Analysis 43:33-36.

Koenig, Mellisa A., Clément, Fabrice, and Harris, Paul L. 2004. "Trust in Testimony: Children's Use of True and False Statements." Psychological Science 15:694698, doi:10.1111/j.0956-7976.2004.00742.x.

Lackey, Jennifer. 2005. "Memory as a Generative Epistemic Source." Philosophy and Phenomenological Research 70:636-658. 
- 2008. Learning from Words: Testimony as a Source of Knowledge. Oxford: Oxford University Press.

Lasonen-Aarnio, Maria. 2010. "Is There a Viable Account of Well-Founded Belief." Erkenntnis 72:205-231, doi:10.1007/s10670-009-9200-z.

—. 2014. "Higher-Order Evidence and the Limits of Defeat." Philosophy and Phenomenological Research 88:314-345.

Lewis, David. 1996. "Elusive Knowledge." Australasian Fournal of Philosophy 74:549567, doi:10.1080/00048409612347521. Reprinted in Papers in Metaphysics and Epistemology, pp. 418-446.

Malmgren, Anna-Sara. 2006. "Is There a Priori Knowledge by Testimony?” Philosophical Review 115:199-241.

Moss, Sarah. 2012. "Updating as Communication." Philosophy and Phenomenological Research 85:225-248, doi:10.1111/j.1933-1592.2011.00572.x.

Pryor, James. 2004. "Is Moore's Argument an Example of Transmission Failure?" Philosophical Issues 14:349-378.

Saffran, Jenny R., Aslin, Richard N., and Newport, Elissa L. 1996a. "Statistical Learning by 8-Month-Old Infants." Science 274:1926-1928.

Saffran, Jenny R., Newport, Elissa L., and Aslin, Richard N. 1996b. "Word Segmentation: The Role of Distributional Cues." Fournal of Memory and Language 35:606-621.

Schmitt, Frederick F. 2006. "Testimonial Justification and Transindividual Reasons." In Jennifer Lackey and Ernest Sosa (eds.), The Epistemology of Testimony, 193224. Oxford University Press.

Sgaravatti, Daniele. 2012. Down to Earth Philosophy: An Anti-Exceptionalist Essay on Thought Experiments and Philosophical Methodology. Ph.D. thesis, University of St Andrews.

Steup, Matthias. 2013. “Is Epistemic Circularity Bad?” Res Philosophica 90:215235, doi:http:// dx.doi.org/ 10.11612/ resphil.2013.90.2.8.

Tetlock, Philip E. and Gardner, Dan. 2015. Superforecasting: The Art and Science of Prediction. New York: Crown.

Titelbaum, Michael. 2014. Quitting Certainties: A Bayesian Framework for Modeling Degrees of Belief. Oxford: Oxford. 
Weatherson, Brian. 2012. "Knowledge, Bets and Interests." In Jessica Brown and Mikkel Gerken (eds.), Knowledge Ascriptions, 75-103. Oxford: Oxford University Press.

White, Roger. 2005. "Explanation as a Guide to Induction." Philosophers' Imprint 5:1-29. http://www . philosophersimprint.org/005002/.

Williamson, Timothy. 2000. Knowledge and its Limits. Oxford University Press.

Wright, Crispin. 2002. "(Anti-)Sceptics Simple and Subtle: G.E. Moore and John McDowell." Philosophy and Phenomenological Research 65:330-348, doi:10.1111/j.1933-1592.2002.tb00205.x.

—. 2004. "Warrant for Nothing (And Foundations for Free)?" Proceedings of the Aristotelian Society, Supplementary Volume 78:167-212. 